\title{
Comparison of high-flow nasal oxygen therapy and noninvasive ventilation in COVID-19 patients: a systematic review and meta-analysis
}

\author{
Glenardi', Febie Chriestya ${ }^{2}$, Bambang J Oetoro ${ }^{3}$, Ghea Mangkuliguna ${ }^{1}$, Natalia ${ }^{1}$ \\ ${ }^{1}$ School of Medicine and Health Sciences and Departments of ${ }^{2}$ Internal Medicine and ${ }^{3}$ Anesthesiology and Critical Care, School of Medicine and Health Sciences, \\ Atma Jaya Catholic University of Indonesia, North Jakarta, Indonesia
}

Background: Acute respiratory failure (ARF) is a major adverse event commonly encountered in severe coronavirus disease 2019 (COVID-19). Although noninvasive mechanical ventilation (NIV) has long been used in the management of ARF, it has several adverse events which may cause patient discomfort and lead to treatment complication. Recently, high-flow nasal cannula (HFNC) has the potential to be an alternative for NIV in adults with ARF, including COVID-19 patients. The objective was to investigate the efficacy of HFNC compared to NIV in COVID-19 patients.

Methods: This meta-analysis was reported following the Preferred Reporting Items for Systematic Reviews and Meta-Analyses (PRISMA) criteria. Literature search was carried out in electronic databases for relevant articles published prior to June 2021. The protocol used in this study has been registered in International Prospective Register of Systematic Reviews (CRD42020225186).

Results: Although the success rate of NIV is higher compared to HFNC (odds ratio [OR], 0.39; 95\% confidence interval $[\mathrm{Cl}], 0.16-0.97 ; \mathrm{P}=0.04)$, this study showed that the mortality in the NIV group is also significantly higher compared to HFNC group (OR, 0.49;95\% $\mathrm{Cl}, 0.39-0.63 ; \mathrm{P}<0.001)$. Moreover, this study also demonstrated that there was no significant difference in intubation rates between the two groups $(\mathrm{OR}, 1.35 ; 95 \% \mathrm{Cl}, 0.86-2.11 ; \mathrm{P}=0.19)$.

Conclusions: Patients treated with HFNC showed better outcomes compared to NIV for ARF due to COVID-19. Therefore, HFNC should be considered prior to NIV in COVID-19-associated ARF. However, further studies with larger sample sizes are still needed to better elucidate the benefit of HFNC in COVID-19 patients.

Key Words: COVID-19; high-flow nasal cannula; meta-analysis; noninvasive ventilation; systematic review

\section{INTRODUCTION}

As the coronavirus disease 2019 (COVID-19) pandemic continues to spread globally, there are already more than 218 million confirmed cases and 4.5 million deaths reported to the World Health Organization in September 2021 [1]. In severe and critical cases of COVID-19, acute respiratory distress syndrome (ARDS) remains one of the most common unwanted

\section{Original Article}

Received: September 25, 2021

Revised November 19, 2021

Accepted November 20, 2021

Corresponding author

Glenardi

School of Medicine and Health

Sciences, Atma Jaya Catholic

University of Indonesia, Pluit Raya

No. 2, North Jakarta 14440,

Indonesia

Tel: +62-21-6693168

Fax: +62-21-6606123

E-mail: glenardihalim@gmail.com

Copyright (c) 2022 The Korean Society of Critical Care Medicine

This is an Open Access article distributed under the terms of Creative Attributions Non-Commercial License (https:// creativecommons.org/li-censes/by-nc/4.0/ which permits unrestricted noncommercia use, distribution, and reproduction in any medium, provided the original work is properly cited. 
events encountered. ARDS develops in $42 \%$ of COVID-19 patients and $61 \%-81 \%$ of those with ARDS requiring intensive care, including advance oxygen therapy $[2,3]$.

Avoiding unnecessary use of invasive ventilation and endotracheal intubation persist a main objective in the management of acute respiratory failure (ARF) as these procedures are associated with severe adverse events and poor outcomes [4]. Therefore, a noninvasive oxygenation strategy has been developed to support oxygenation and tackle the negative outcomes which are often found in the invasive strategy [5]. Noninvasive mechanical ventilation (NIV) is one of the alternative respiratory support strategies to invasive mechanical ventilation in ARF. However, the use of NIV has several potential adverse events, such as sputum retention, difficulty in synchronizing breathing and skin damage over the bridge of the nose which may cause discomfort and lead to the discontinuation of NIV to some extent [6]. In recent years, high-flow nasal cannula (HFNC), a newly introduced noninvasive oxygenation device, is also deemed to have the potential to be an alternative for NIV in adults with ARF. HFNC was found to be non-inferior to NIV in reducing the need for invasive ventilation among adults with ARF [7]. Furthermore, a randomized control study also reported that the intubation rate and mortality rate were lower with HFNC than with NIV [8].

In COVID-19 setting, HFNC has been recommended by The Asian Critical Care Clinical Trials Group as an alternative to NIV in COVID-19 patient with ARF [9]. Despite the weak recommendation, The Surviving Sepsis Campaign COVID-19 subcommittee also recommended HFNC to be the first line oxygen therapy for COVID-19 patients as it has been suggested to be superior to NIV by most of the experts [10]. These recommendations might be made based on recent satisfactory results regarding the use of HFNC in COVID-19 patients. Several studies showed that HFNC was found to be non-inferior to NIV for reducing the intubation rate and mortality rate in COVID-19 patients [11-13]. Moreover, some studies even found that HFNC was superior to NIV if used in appropriate patients $[8,14]$. Hence, it can be postulated that HFNC has the potential to be the preferred treatment prior to NIV in COVID-19-associated ARF. However, there is still limited evidence supporting the advantages of HFNC over NIV in COVID-19 patients. Hence, we design a systematic review of existing studies and perform a meta-analysis to further investigate and measure the efficacy of HFNC compared to NIV in COVID-19 patients.

\section{KEY MESSAGES}

- High-flow nasal cannula (HFNC) has demonstrated a remarkable ability to match noninvasive mechanical ventilation (NIV) in terms of preventing intubation and even showed more satisfactory results in preventing mortality.

- HFNC should be considered prior to NIV in coronavirus disease 2019 (COVID-19)-associated acute respiratory failure.

- Due to relatively small sample size, further studies with larger sample sizes are still needed to more clearly elucidate the benefit of HFNC in COVID-19 patients.

\section{MATERIALS AND METHODS}

\section{Study Registration and Methodology}

This meta-analysis was reported following the Preferred Reporting Items for Systematic Reviews and Meta-Analyses (PRISMA) criteria [15]. As this paper did not directly involve human subjects, while only using data from published articles, institutional review board approval was not required. The protocol used in this study has been registered in the International Prospective Register of Systematic Reviews (PROSPERO) (CRD42020225186).

\section{Eligibility Criteria}

The following criteria were considered for studies' eligibility: type of study, population, intervention, comparison, and outcome. All types of clinical studies (randomized or non-randomized clinical trials, cohort, case control and cross-sectional) evaluating the use of HFNC and NIV in the COVID-19 patients were included for this study. Case series, case report, reviews and commentary articles were excluded. The participants of this study are subjects diagnosed with COVID-19 and eligible for the use of advanced oxygen therapy. There were no restrictions on age, races, occupation, economy or social status, religion, country, underlying conditions etc. Studies evaluating HFNC as the oxygen therapy for COVID-19 patients were included for this study. Comparators included COVID-19 patients who were treated with NIV. Outcomes of interest were success rate, intubation rate and mortality rate of HFNC compared to NIV in COVID-19 patients. Success rate is defined as the percentage of successes of HFNC or NIV in providing oxygen to the patient without the need to switch to another oxygen-assisted modality. Intubation rate is defined as the 
percentage of intubations performed due to the deterioration of the patient after HFNC or NIV has been installed. Mortality rate is defined as the number of deaths among each group.

\section{Data Sources and Study Selection}

Literature search was carried out with multiple electronic databases, such as Medline, ScienceDirect, EBSCO, and ProQuest to identify articles published up to December 2020. The search was performed by five researchers (G, GM, N, FC, BJO). No time and language restriction were applied. The keywords used were presented in Supplementary Table 1.

After removing duplicates, five reviewers independently screened the titles and abstracts according to the eligibility criteria described above. Thereafter, potentially eligible fulltext articles were thoroughly checked by four independent reviewers before including them into the analysis. Reasons for excluding studies were documented. Any emerging discrepancies would be resolved by consensus among the review team. A PRISMA flowchart describing the study selection process was provided. The planned procedure was illustrated in Figure 1.

\section{Data Extraction}

At least two reviewers independently extracted the data from eligible articles identified during the screening process. In case of disagreements occurred, it would be resolved through discussion until a consensus was achieved. The following data were extracted from the studies: (1) first author and publication year; (2) region; (3) study design; (4) sample size; (5) sample characteristics (age, sex, pre-existing conditions); (6) $\mathrm{PaO}_{2} /$ $\mathrm{FiO}_{2}$; (7) duration of HFNC; (8) duration of NIV; and (9) quality assessment.

\section{Quality Assessment and Reliability of Data}

Version 2 of Cochrane Risk of Bias (ROB-2) tool was used to assess the quality of randomized controlled trial [16]. Meanwhile, Newcastle-Ottawa scale (NOS) was used to evaluate the quality of observational studies [17]. Five researchers (G, GM, $\mathrm{N}, \mathrm{FC}, \mathrm{BJO}$ ) independently evaluate the quality of each study with any discrepancies resolved through discussion.

Trial sequential analysis (TSA) was performed to determine the required sample size and confirm whether the result of meta-analysis was conclusive. TSA generated thresholds for

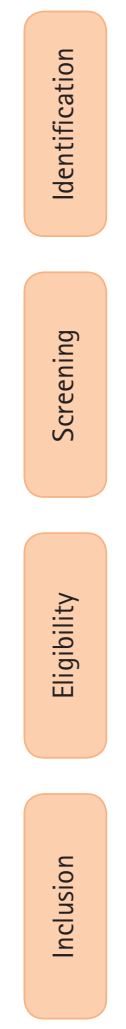

3,299 Records identified through database searching

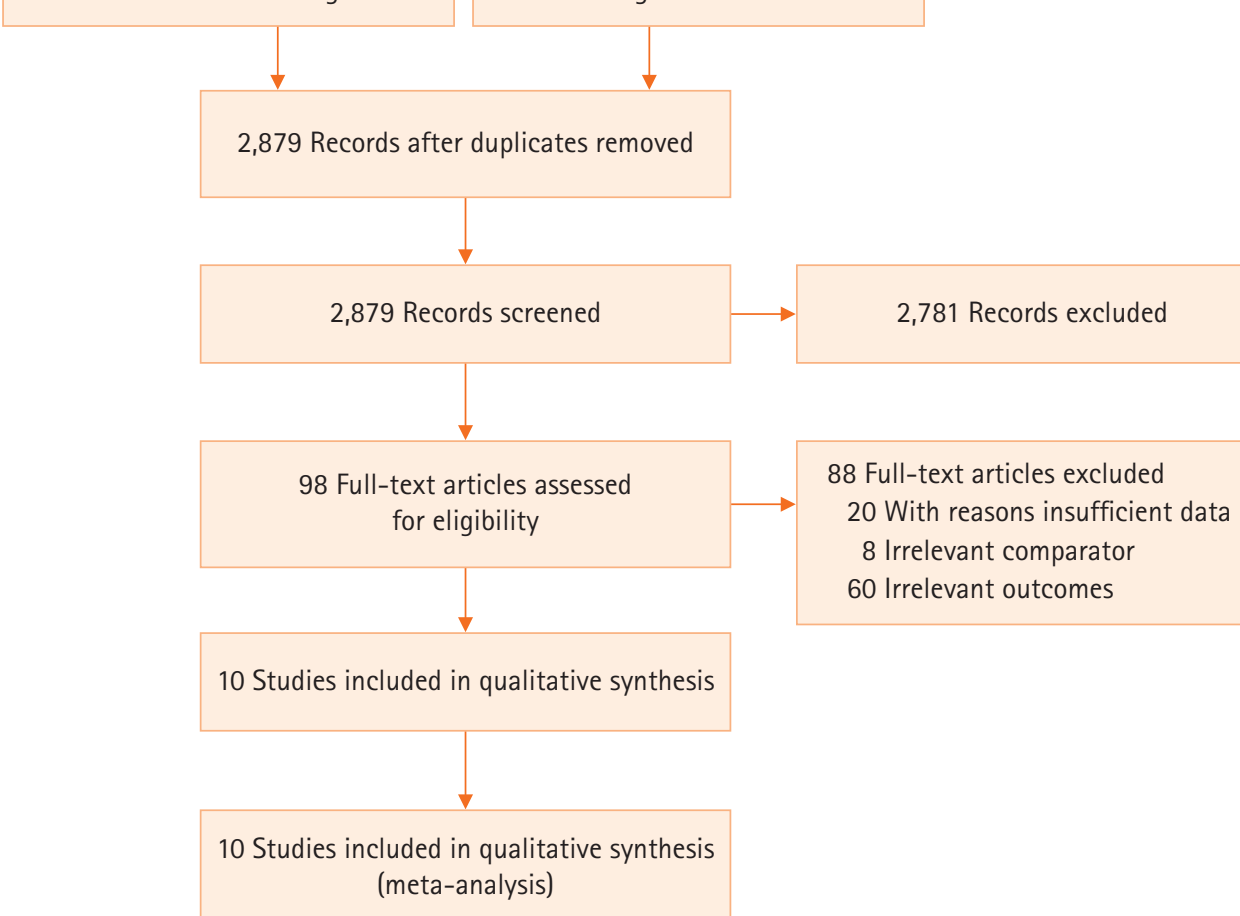

907 Additional records identified through other sources
60 Irrelevant outcomes

88 Full-text articles excluded 20 With reasons insufficient data

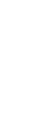

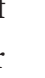


declaring significance of the result to avoid the overestimation of intervention effects and prevent spurious results. The findings were represented by the cumulative Z-curves. When the cumulative Z-curves surpassed the futility boundary, the level of evidence was adequate and further trials will be judged as futile. The level of evidence was judged as adequate and conclusive, if the Z-curves surpassed the conventional and trial sequential significance boundaries. On the contrary, when Z-curves did not cross any boundaries or only surpassed the conventional boundary, the level of evidence was inadequate and more trials were required to clarify the conclusion. A two-sided trial sequential monitoring boundary type was used in our TSA. The required information size was calculated with $\alpha=0.05$. TSA was performed using TSA version 0.9 .5 .10 beta [18].

\section{Data Synthesis and Statistical Analysis}

Odds ratio (OR) with a confidence interval (CI) of $95 \%$ was used to determine the efficacy of HFNC compared to NIV in COVID-19 patients. OR was considered significant if the value was not equal to 1 with $\mathrm{P}<0.05$. Random effects model was used for the analysis and the combined effect size was plotted using a forest plot. Heterogeneity of included studies are assessed using Cochrane's Q Test (chi-square) of homogeneity and Higgins $\mathrm{I}^{2}$ statistics. Subgroup analysis would be conducted to find the possible cause of heterogeneity. Funnel plot was used to assess publication bias visually. Asymmetric funnel plot indicated the possibility of publication bias. This would be confirmed through Begg and Mazumdar rank correlation test and Egger's test of the intercept to determine the presence of publication bias statistically. If publication bias was observed, Duval and Tweedie's trim and fill method would be used to correct the bias. Furthermore, sensitivity analysis was performed in order to confirm the robustness of this meta-analysis. All statistical tests were done using RevMan 5.3 (Cochrane Collaboration, London, UK) [19].

\section{Confidence in Cumulative Evidence}

Grading of Recommendations, Assessment, Development, and Evaluations (GRADE) was used to determine the confidence in cumulative evidence. Judgement was made considering the presence of study limitations, consistency, directness, imprecision, and/or reporting bias. Overall certainty of evidence was shown as high, moderate, low, or very low quality.

\section{RESULTS}

\section{Search Results}

Initial search from the electronic database yielded 4,206 studies, of which 1,327 were duplicates and therefore excluded. The remaining 2,879 articles were screened through titles and abstracts. Moreover, a total of 2,781 studies were excluded as it was found to be irrelevant to the topic of our study and 98 studies were further assessed for eligibility. At last, 10 studies were included in our systematic review and meta-analysis. The searching strategy and selection methods of this study were illustrated in Figure 1.

\section{Study Characteristics}

The majority of included studies are conducted in China (4 studies) $[11,14,20,21]$, followed by Switzerland (2 studies) [22,23], Belgium (1 study) [24], France (1 study) [24], Italy (2 study) [12,25], Austria (1 study) [24], Greece (1 study) [26]. One included study was a randomized clinical trial and the rest of the included studies were categorized as observational study, which were either prospective or retrospective. Six included studies were a multi-center study and the rest were a single-center study. The participants were adults with ages ranging from 36 to 75 years old. All the study participants showed $\mathrm{PaO}_{2} / \mathrm{FiO}_{2}$ ratio under $300 \mathrm{~mm} \mathrm{Hg}$ [27]. Characteristics of included studies were presented in Table 1.

\section{Methodological Quality}

A randomized controlled trial was evaluated using Cochrane ROB-2 and judged to have low risk of bias. Quality assessment of the observational studies were conducted using NOS. Based on the findings, the overall quality of all included studies was considered as good with a mean score of 8 . There were four studies which did not provide adequate information regarding the follow up of the cohort study. However, it did not affect the overall quality of evidence of these studies because the other point of outcomes' assessments was provided with adequate information $[14,21,24,26]$. A complete summary of the quality assessment was presented in Table 2 and Supplementary Figure 1.

\section{Mortality Rate}

A meta-analysis of nine studies which was presented in Figure 2A showed THAT HFNC was associated with a lower mortality rate compared to NIV (OR, 0.49; 95\% CI, 0.39-0.63; $\mathrm{P}<0.001$; $\mathrm{I}^{2}$, $0 \%)$. Moreover, TSA also confirmed this result as the cumula- 


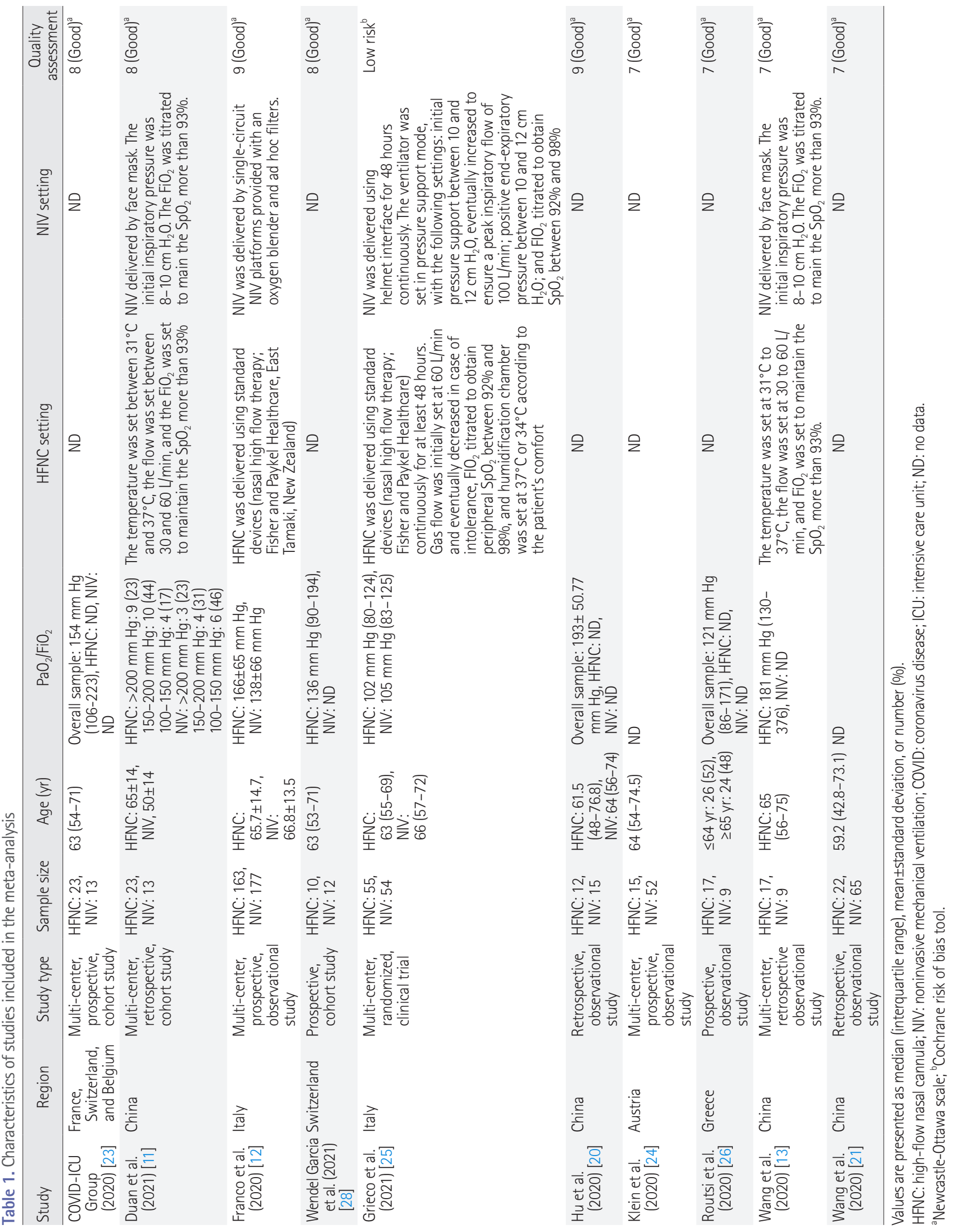


Table 2. Methodological quality (observational studies)

\begin{tabular}{|c|c|c|c|c|c|c|c|c|c|}
\hline \multirow[b]{2}{*}{ Study } & \multicolumn{4}{|c|}{ Selection } & \multirow{2}{*}{$\begin{array}{l}\text { Comparability } \\
\text { Comparability } \\
\text { of cohorts } \\
\text { based on design } \\
\text { and analysis }\end{array}$} & \multicolumn{3}{|c|}{ Outcome } & \multirow[b]{2}{*}{$\begin{array}{c}\text { Overall } \\
\text { quality } \\
\text { assessment }^{\mathrm{a}}\end{array}$} \\
\hline & $\begin{array}{c}\text { Representative } \\
\text { of exposed } \\
\text { cohort }\end{array}$ & $\begin{array}{c}\text { Selection of } \\
\text { non-exposed } \\
\text { cohort }\end{array}$ & $\begin{array}{c}\text { Ascertainment } \\
\text { of exposure }\end{array}$ & $\begin{array}{l}\text { Demonstration } \\
\text { that outcome } \\
\text { was not present } \\
\text { at start of study }\end{array}$ & & $\begin{array}{l}\text { Assessment } \\
\text { of outcome }\end{array}$ & $\begin{array}{l}\text { Timing of } \\
\text { follow-up }\end{array}$ & $\begin{array}{l}\text { Adequate } \\
\text { follow-up }\end{array}$ & \\
\hline $\begin{array}{l}\text { COVID-ICU group } \\
\text { (2020) [23] }\end{array}$ & $\star$ & $\star$ & $\star$ & $\star$ & $\star$ & $\star$ & $\star$ & $\star$ & 8 (Good) \\
\hline Duan et al. (2021) [11] & $\star$ & $\star$ & $\star$ & $\star$ & $\star$ & $\star$ & $\star$ & $\star$ & 8 (Good) \\
\hline Franco et al. (2020) [12] & $\star$ & $\star$ & $\star$ & $\star$ & $\star \star$ & $\star$ & $\star$ & $\star$ & 9 (Good) \\
\hline $\begin{array}{l}\text { Wendel Garcia et al. } \\
\text { (2021) [28] }\end{array}$ & $\star$ & $\star$ & $\star$ & $\star$ & $\star$ & $\star$ & $\star$ & $\star$ & 8 (Good) \\
\hline Hu et al. (2020) [20] & $\star$ & $\star$ & $\star$ & $\star$ & $\star \star$ & $\star$ & $\star$ & $\star$ & 9 (Good) \\
\hline Klein et al. (2020) [24] & $\star$ & $\star$ & $\star$ & $\star$ & $\star$ & $\star$ & $\star$ & & 7 (Good) \\
\hline Routsi et al. (2020) [26] & $\star$ & $\star$ & $\star$ & $\star$ & $\star$ & $\star$ & $\star$ & & 7 (Good) \\
\hline Wang K et al. (2020) [13] & $\star$ & $\star$ & $\star$ & $\star$ & $\star$ & $\star$ & $\star$ & & 7 (Good) \\
\hline Wang Z et al. (2020) [21] & $\star$ & $\star$ & $\star$ & $\star$ & $\star$ & $\star$ & $\star$ & & 7 (Good) \\
\hline
\end{tabular}

COVID: coronavirus disease; ICU: intensive care unit.

aThresholds for converting the Newcastle-Ottawa scales to Agency for Healthcare Research and Quality standards (good, fair, and poor). Good quality: 3 or 4 stars in selection domain; and 1 or 2 stars in comparability domain; and 2 or 3 stars in outcome/exposure domain; Fair quality: 2 stars in selection domain; and 1 or 2 stars in comparability domain; and 2 or 3 stars in outcome/exposure domain; Poor quality: 0 or 1 star in selection domain; or 0 stars in comparability domain; or 0 or 1 stars in outcome/exposure domain.

tive Z-curve surpassed the conventional significance boundary as well as the trial sequential significance boundary (Figure 2B). Moreover, the cumulative Z-curve also surpassed the required meta-analysis sample size with a minimal participant of 1,524 . Thus, the result was conclusive and no further trials are required.

In addition, we also further evaluate the mortality rate of HFNC when used as a first-line oxygen therapy for severe-to-critical COVID-19 patients. Four studies demonstrated that the mortality rate in the HFNC group was significantly lower than the NIV group (OR, 0.45; 95\% CI, 0.27-0.75; $\left.\mathrm{P}=0.002 ; \mathrm{I}^{2}, 0 \%\right)$ in patient who received HFNC and NIV as their first line oxygen therapy (Figure 3A). TSA also confirmed the result as the cumulative Z-curve surpassed the conventional significance boundary as well as the trial sequential significant boundary which implied that the type I and type II error was avoided. Furthermore, the cumulative Z-curve has also reached the required meta-analysis sample size with a minimal participant of 376 (Figure 3B) Thus, it could be inferred that the result was conclusive and no further trials were required.

\section{Success Rate}

Three studies demonstrated that NIV had a higher success rate than HFNC. The pooled analysis which was presented in Figure $4 \mathrm{~A}$, proposed that the success rate of NIV was significantly higher than the HFNC (OR, 0.39; 95\% CI, 0.16-0.97; $\mathrm{P}=0.04 ; \mathrm{I}^{2}$, $0 \%)$. In addition, TSA was also conducted to further confirm the result. As seen in Figure 4B, the cumulative Z-curve only surpassed the conventional significance boundary and did not surpass the trial sequential significant boundary which implied that type II error was not avoided. Moreover, the cumulative Z-curve also did not reach the required meta-analysis sample size with a minimal participant of 495 . Thus, it could be inferred that the result was still inconclusive and further trials were required.

\section{Intubation Rate}

In this study, we found that HFNC was non-inferior to NIV in reducing the need for intubation. As seen in Figure 5A, a meta-analysis of four studies demonstrated that the outcome of HFNC similar to NIV with respect to the intubation rate (OR, 1.35; 95\% CI, 0.86-2.11; $\mathrm{P}=0.19$; $\mathrm{I}^{2}, 9 \%$ ). To further confirm the result, TSA was also conducted and showed that the cumulative Z-curve did not cross any boundaries which implies that type I and II error were not avoided. Moreover, the cumulative Z-curve also did not reach the required meta-analysis sample size with a minimal participant of 1,684 (Figure 5B). Therefore, the result was still inconclusive and further trials are required.

\section{Confidence in Cumulative Evidence}

Overall studies were judged to have good quality according to 
(4)

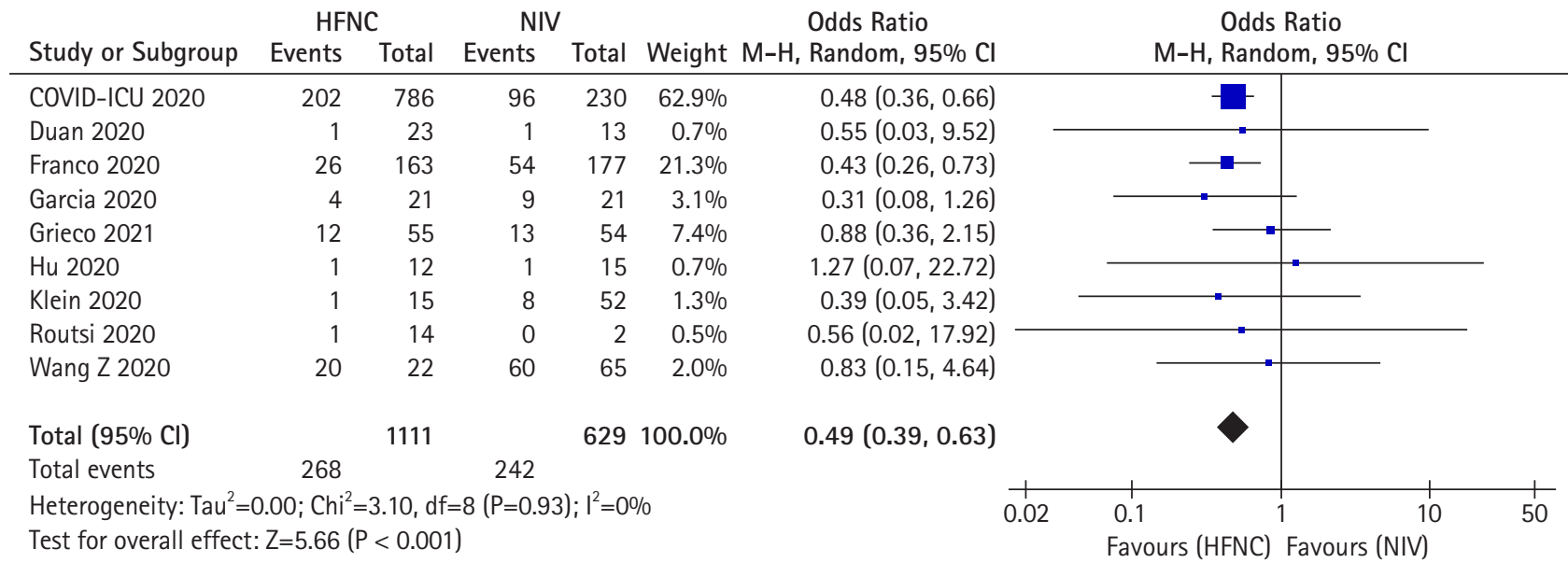

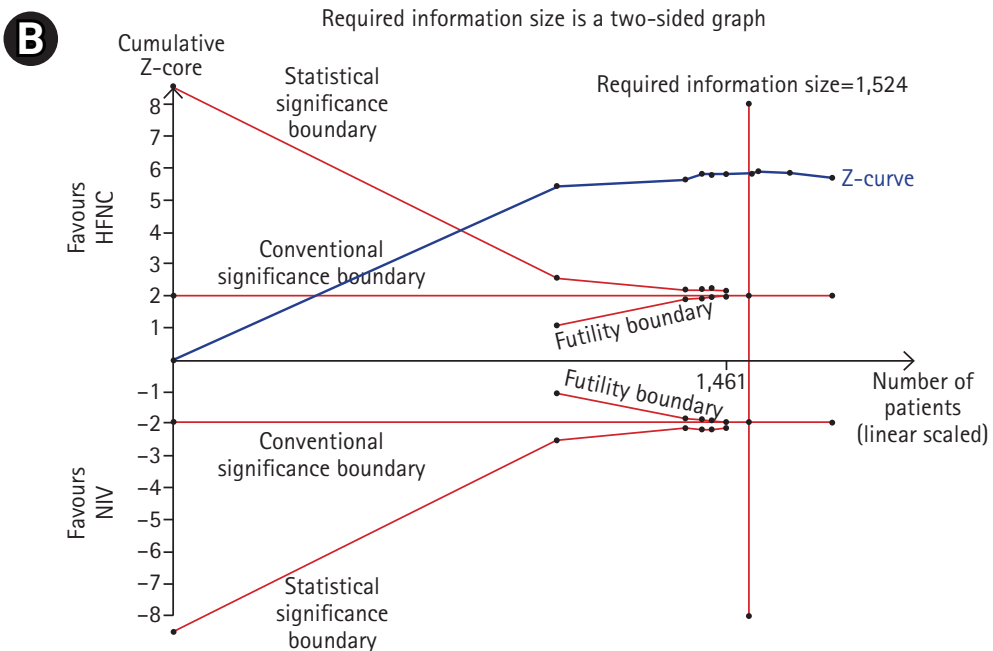

Figure 2. Mortality rate of high-flow nasal cannula (HFNC) compared to noninvasive mechanical ventilation (NIV) if used as the first line therapy or rescue therapy. The mortality rate demonstrated in this figure ranges from 28-day to 90-day mortality rate. (A) Forest plot depicting HFNC compared to NIV on mortality rate in general. The results demonstrate a difference in mortality rate using a random effects model comparing HFNC vs. NIV. (B) Trial sequential analysis comparing success rate between HFNC and NIV. A 39.8\% control event rate and a 52.9\% relative risk reduction with 95\% power and a two-sided $\alpha=0.05$ were assumed. The trial sequential boundary, futility boundary and the required meta-analysis sample size boundary were not renderable due to the first information fraction exceeded $100 \%$ of the required information size. The cumulated Z-curve (blue) only surpassed the conventional significance boundary, indicating type II error was not avoided and the result was still inconclusive. $\mathrm{Cl}$ : confidence interval.

NOS and Cochrane ROB2, hence plausible bias was unlikely to seriously alter the results. In addition, we did not observe any serious inconsistency and indirectness that could affect the whole results. However, we observed imprecision in some of the outcomes. Most individual studies assessing the success rate and intubation rate were found to have a wide CI and inconclusive TSA results. The publication bias could not be assessed in all of the outcomes as the number of included studies did not reach 10 . Overall, we had very low-to-moderate quality of evidence in this meta-analysis. GRADE evidence profile was generated as shown in Table 3 .

\section{DISCUSSION}

With 10 studies and 1,766 COVID-19 patients included, this study demonstrated that HFNC was superior to NIV in terms of decreasing mortality, especially when used as the first-line oxygen therapy for COVID-19 patients. These findings were in accordance with the previous studies which showed that therapy using HFNC decrease mortality rate compared to using NIV in adults with ARF $[9,14,29]$. There are several reasons that may explain this finding, but the most convincing evidence is that NIV has been proven to increase the risk for volutrauma $[9,29]$. NIV can deliver pressure higher than the 


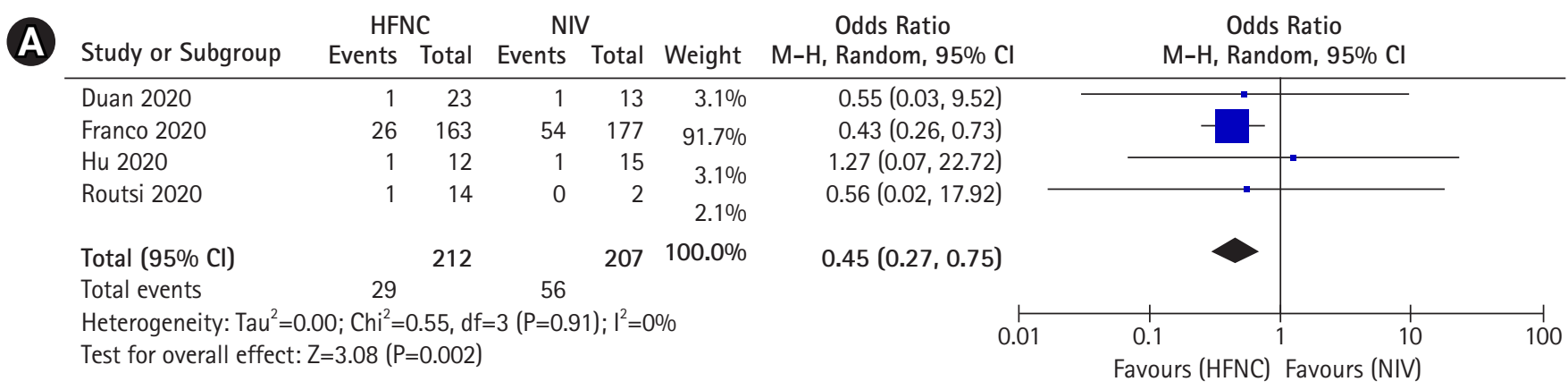

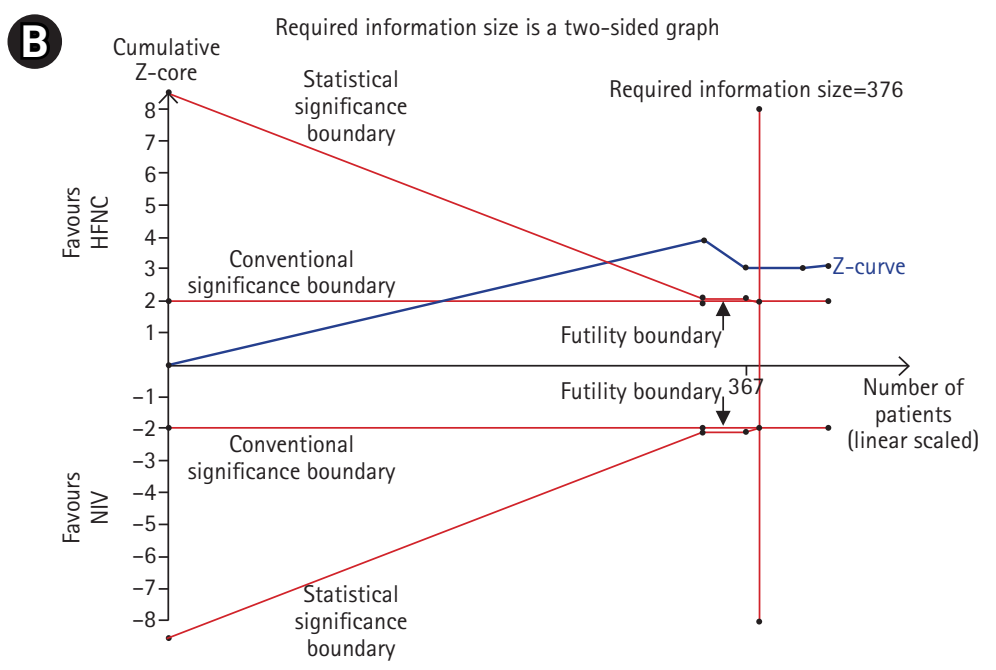

Figure 3. Mortality rate of high-flow nasal cannula (HFNC) compared to noninvasive mechanical ventilation (NIV) if used as the first line therapy only. (A) Forest plot depicting HFNC compared to NIV on mortality rate when used as the first line oxygen therapy. The results demonstrate a difference in mortality rate using a random effects model comparing HFNC vs. NIV. (B) Trial sequential analysis comparing success rate between HFNC and NIV. A 27\% control event rate and a 54.8\% relative risk reduction with 95\% power and a two-sided $\alpha=0.05$ were assumed. The cumulated Z-curve (blue) surpassed the conventional significance boundary, trial sequential boundary and the required meta-analysis sample size boundary, indicating that the cumulative evidence is conclusive and no further trials are needed. $\mathrm{Cl}$ : confidence interval.

targeted tidal volume which will result in higher transpulmonary driving pressure and inspiratory effort. These conditions will eventually cause patient self-inflicted lung injury which detrimentally affects the patient's outcome, thereby increasing mortality [30,31]. In contrast, HFNC ensures a more reliable delivery of desired $\mathrm{FiO}_{2}$ than NIV by preventing the entry of room air during patient inspiration [32]. Thus, it will flushedout $\mathrm{CO}_{2}$ continuously from the upper airway and eliminates the anatomical dead space, further increasing the efficiency of ventilation.

Furthermore, HFNC also provides a small amount of positive end-expiratory pressure (PEEP) which may counterbalance auto-PEEP and reduce the inspiratory effort [33,34]. By combining the washout effect on the upper airway and the generation of a small PEEP, HFNC is able to decrease the work of breathing and improve the ventilation and perfusion match- ing without increasing tidal volume [34]. Therefore, HFNC may have a lower risk of aggravating lung injury as it prevents excessive lung expansion. Another possible reason is that HFNC has a more superior effect on airway secretion. In patients with pneumonia, management of airway secretion is essential as sputum retention can lead to airway obstruction which can adversely affect the clinical outcome. By delivering humidified gas, HFNC helps optimize mucosal clearance, controlling secretions volume and facilitating cough thereby preventing atelectasis [35]. On the contrary, NIV is reported to be unable to improve sputum clearance [36]. However, it should be noted that the use of HFNC in different cases is not consistently associated with lower mortality. In a recent Cochrane review comparing the efficacy of HFNC with standard oxygen therapy and NIV in adult intensive care patients, HFNC was shown to not exhibit significantly lower mortality and better outcomes 


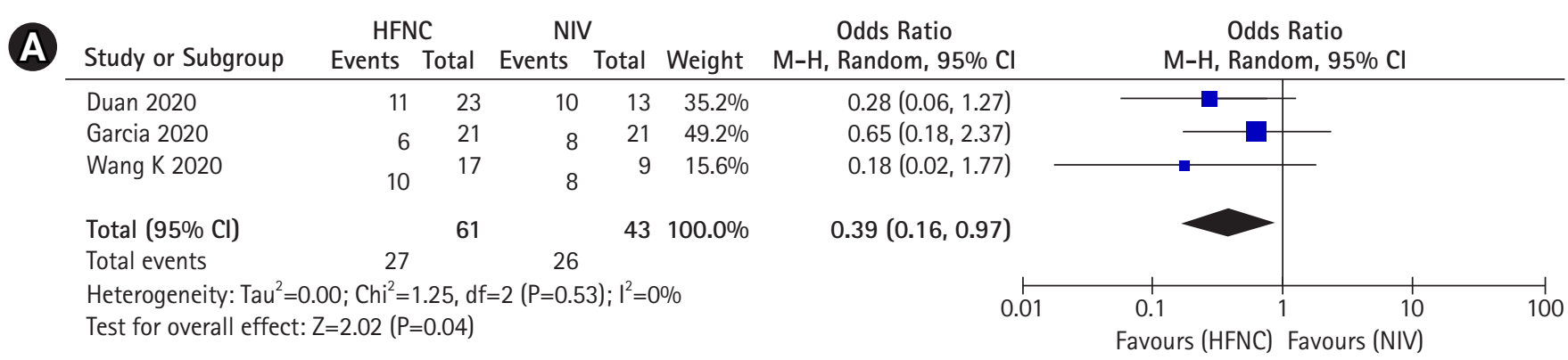

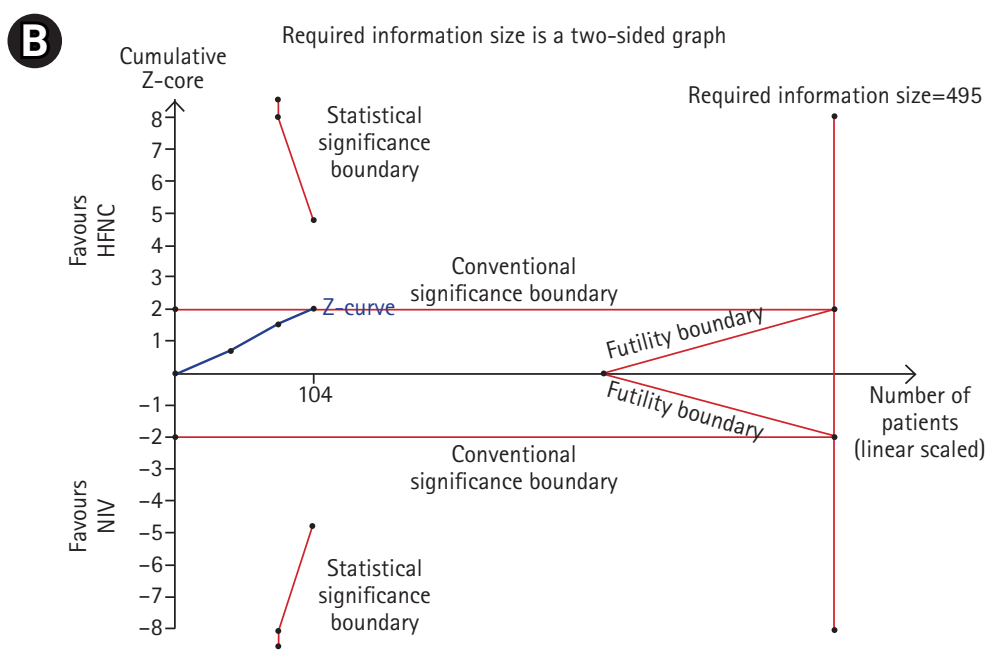

Figure 4. Success rate of high-flow nasal cannula (HFNC) compared to noninvasive mechanical ventilation (NIV). (A) Forest plots of patients who receive HFNC and NIV as their oxygen therapy. Events showed patients who succeeded to achieve their therapeutic goal. The results demonstrate a difference in success rate using a random effects model comparing HFNC vs. NIV. (B) Trial sequential analysis comparing success rate between HFNC and NIV. A $60.4 \%$ control event rate and a $26.8 \%$ relative risk reduction with $95 \%$ power and a two-sided $\alpha=0.05$ were assumed. The cumulated Z-curve (blue) only surpassed the conventional significance boundary, indicating type II error was not avoided and the result was still inconclusive. The required meta-analysis sample size boundary was also not surpassed, indicating further trials are needed. Cl: confidence interval.

compared with other modalities [37].

This study also showed that HFNC had a similar outcome to NIV in terms of the need for intubation. On the other hand, this result contradicts another study showing lower intubation rates in the HFNC group compared to the NIV group. However, this finding might be explained by the prolonged use of non-invasive ventilation described in this study which consequently resulted in delayed intubation and led to lower intubation rates due to higher mortality rates without intubation [28]. However, the difference in intubation rates between HFNC and NIV in this study was shown to be inconclusive in the TSA and thus further trials are required.

Despite having several advantages over NIV, our study oddly found that HFNC had a lower success rate than NIV to achieve the desired therapeutic goal. This finding is not surprising as another study has also reported a similar result when comparing HFNC and NIV as the first-line therapy for ARF [30]. However, it should be noted that the primary goal in the man- agement of ARF is to prevent patient deterioration and thereby reduce mortality. Although the success rate of NIV is higher compared to HFNC, the mortality in the NIV group is also significantly higher. Therefore, if faced with a choice, it would be more appropriate to prioritize HFNC over NIV to be the first line oxygen therapy in COVID-19-associated ARF.

The overall quality of evidence was identified as very low-to-moderate. There were inconsistencies for the analysis of success rate and intubation rate. A possible explanation was the small number of subjects used in individual studies or low variability of the population. Due to some inconsistencies, we suggest a weak recommendation for using HFNC as an alternative to NIV in COVID-19 patients.

Strengths of our review include that this is the first meta-analysis that comprehensively compared the efficacy of HFNC and NIV in COVID-19 patients. This study provides early evidence that HFNC may be the preferred modality prior to NIV for COVID-19 patients. However, this study also has sever- 
(4)

Study or Subgroup

HFNC

NIV

Odds Ratio

Odds Ratio

Duan 2020

Events Total Events

Total Weight $\mathrm{M}-\mathrm{H}$, Random, 95\% C

Franco 2020

Grieco 2021

Wang K 2020

423

$2 \quad 13-5.7 \%$

$1.16(0.18,7.38)$

$1.06(0.66,1.70)$

$\begin{array}{rrrrr}4 & 23 & 2 & 13 & 5.7 \% \\ 28 & 163 & 49 & 177 & 63.1 \% \\ 2 & 55 & 16 & 54 & 28.1 \% \\ & 17 & 1 & 9 & 3.1 \%\end{array}$

$2.46(1.12,5.42)$

$1.07(0.08,13.65)$

Total $(95 \% \mathrm{Cl})$

258

$253 \quad 100.0 \%$

$1.35(0.86,2.11)$

Total events

81

68

Heterogeneity: $\operatorname{Tau}^{2}=0.02 ; \mathrm{Chi}^{2}=3.29, \mathrm{df}=3(\mathrm{P}=0.35) ; \mathrm{I}^{2}=9 \%$

Test for overall effect: $Z=1.31 \quad(P=0.19)$

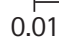

Favours (HFNC) Favours (NIV)

$\mathrm{M}-\mathrm{H}$, Random, 95\% Cl

B

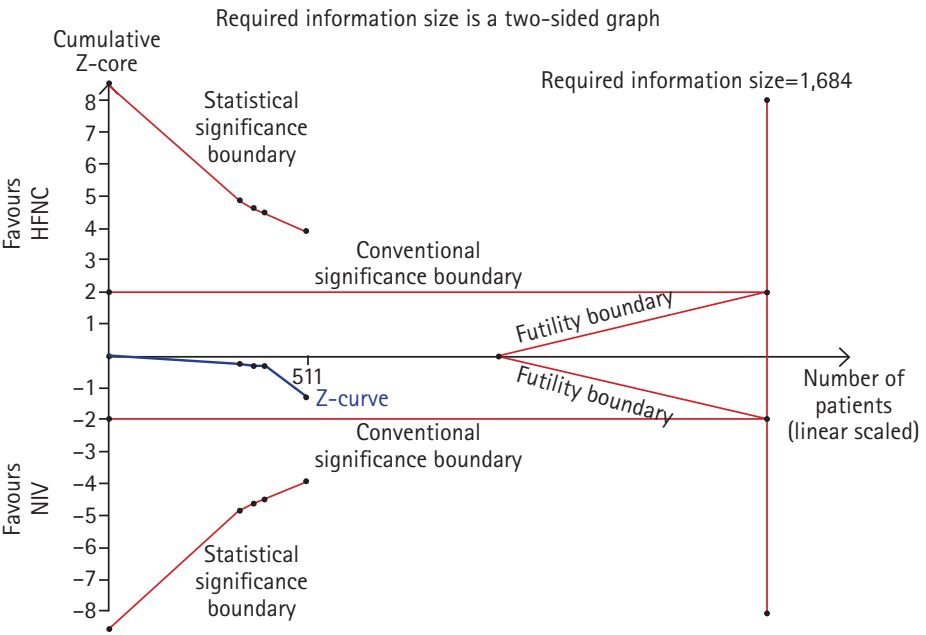

Figure 5. Intubation rate of high-flow nasal cannula (HFNC) compared to noninvasive mechanical ventilation (NIV). (A) Forest plot depicting HFNC compared to NIV on intubation rate. The results demonstrate no difference in intubation rate was noted using a random effects model. (B) Trial sequential analysis comparing success rate between HFNC and NIV. A 26.1\% control event rate and a 6.4\% relative risk reduction with 95\% power and a two-sided $\alpha=0.05$ were assumed. The trial sequential boundary, futility boundary and the required meta-analysis sample size boundary were not renderable due to too little information use (1.11\%) during the analysis. The cumulated Z-curve (blue) did not surpass any boundary, indicating and the result was still inconclusive. Cl: confidence interval.

Table 3. GRADE evidence profile (HFNC compared to NIV for COVID-19 patients)

\begin{tabular}{|c|c|c|c|c|c|c|c|c|c|c|}
\hline \multirow{3}{*}{ Outcome } & \multirow{3}{*}{$\begin{array}{l}\text { No. of } \\
\text { participants } \\
\text { (studies) }\end{array}$} & \multicolumn{6}{|c|}{ Quality assessment } & \multicolumn{3}{|c|}{ Summary of findings } \\
\hline & & \multirow{2}{*}{$\begin{array}{c}\text { Risk of bias } \\
\text { (NOS, Cochrane } \\
\text { ROB2) }\end{array}$} & \multirow{2}{*}{ Inconsistency } & \multirow{2}{*}{ Indirectness } & \multirow{2}{*}{ Imprecision } & \multirow{2}{*}{$\begin{array}{l}\text { Publication } \\
\text { bias }\end{array}$} & \multirow{2}{*}{$\begin{array}{l}\text { Overall } \\
\text { quality of } \\
\text { evidence }\end{array}$} & \multicolumn{2}{|c|}{ Study event rate } & \multirow[b]{2}{*}{ OR $(95 \% \mathrm{Cl}$} \\
\hline & & & & & & & & HFNC/total & NIV/total & \\
\hline \multirow[t]{2}{*}{ Success rate } & \multirow[t]{2}{*}{$\begin{array}{l}104 \text { (3 cohort } \\
\text { studies) }\end{array}$} & \multirow[t]{2}{*}{ Not serious } & \multirow[t]{2}{*}{ Not serious } & \multirow[t]{2}{*}{ Not serious } & \multirow[t]{2}{*}{ Serious $^{a}$} & \multirow[t]{2}{*}{$N A^{b}$} & Very low & \multirow[t]{2}{*}{$27 / 61$} & \multirow[t]{2}{*}{$26 / 43$} & \multirow[t]{2}{*}{$\begin{array}{c}0.39 \\
(0.16-0.97)\end{array}$} \\
\hline & & & & & & & Very low & & & \\
\hline Intubation rate & $\begin{array}{l}511 \text { (1 RCT, } 3 \\
\text { cohort studies) }\end{array}$ & Not serious & Not serious & Not serious & Serious $^{a}$ & $N A^{b}$ & $\begin{array}{l}\text { Very low } \\
\text { Low }\end{array}$ & $81 / 258$ & $68 / 253$ & $\begin{array}{c}1.35 \\
(0.86-2.11)\end{array}$ \\
\hline $\begin{array}{l}\text { Mortality rate in } \\
\text { general }\end{array}$ & $\begin{array}{l}\text { 1,740 (1 RCT, } 8 \\
\text { cohort studies) }\end{array}$ & Not serious & Not serious & Not serious & Not serious $^{\mathrm{a}}$ & $N A^{b}$ & $\begin{array}{l}\text { Very low } \\
\text { Moderate }\end{array}$ & $268 / 1,111$ & $242 / 629$ & $\begin{array}{c}0.49 \\
(0.39-0.63)\end{array}$ \\
\hline $\begin{array}{l}\text { Mortality rate if } \\
\text { used as first- } \\
\text { line therapy }\end{array}$ & $\begin{array}{l}419 \text { ( } 4 \text { cohort } \\
\text { studies) }\end{array}$ & Not serious & Not serious & Not serious & Not serious $^{\mathrm{a}}$ & $N A^{b}$ & $\begin{array}{l}\text { Very low } \\
\text { Low }\end{array}$ & $29 / 212$ & $56 / 207$ & $\begin{array}{c}0.45 \\
(0.27-0.75)\end{array}$ \\
\hline
\end{tabular}

GRADE: Grading of Recommendations, Assessment, Development, and Evaluations; HFNC: high-flow nasal cannula; NIV: noninvasive mechanical ventilation; COVID-19: coronavirus disease 2019; NOS: Newcastle-Ottawa scale; OR: odds ratio; Cl: confidence interval; NA: not applicable; RCT: randomized controlled trial. ${ }^{a}$ Most of the individual studies have a wide $\mathrm{Cl}$ and affected the overall $\mathrm{Cl}$ to be wide. TSA was inconclusive; ${ }^{b}$ Publication bias could not be determined as the number of studies was less than 10. 
al limitations. First, the majority of included studies are observational studies where the characteristics of both groups were not controlled. Second, this study only compared HFNC with NIV in general, thus the comparison results are less specific. Third, this study was unable to provide important information regarding the HFNC/NIV settings and PF ratio in some of the included studies. Lastly, only one randomized clinical trial as the highest position on the evidence pyramid was included in this meta-analysis. These limitations support the need for further larger studies to provide credible results.

HFNC has been shown to be effective as an oxygen delivery modality for ARF. Among severe-to-critical COVID-19 patients, ARF is one of the most common unwanted events encountered and must be treated immediately. In this study, HFNC demonstrated a remarkable ability to significantly decrease the intubation rate and have a lower mortality. By knowing the effectiveness of HFNC in COVID-19 patients, our data suggested that HFNC should be considered prior to NIV in COVID-19associated ARF. However, further clinical and physiological studies are still needed to more clearly elucidate the benefit of HFNC in COVID-19 patients.

\section{CONFLICT OF INTEREST}

No potential conflict of interest relevant to this article was reported.

\section{ORCID}

Glenardi https://orcid.org/0000-0001-7360-6634

Febie Chriestya https://orcid.org/0000-0001-8414-3743

Bambang J Oetoro https://orcid.org/0000-0001-9929-9564

Ghea Mangkuliguna

Natalia

https://orcid.org/0000-0002-3436-0624

https://orcid.org/0000-0002-5249-225X

\section{AUTHOR CONTRIBUTIONS}

Conceptualization: G, BJO. Data curation: all authors. Formal analysis: G, GM, BJO. Methodology: G, GM, N. Project administration: all authors. Visualization: G, FC, N. Writing/original draft: all authors. Writing-review \& editing: G, FC, BJO.

\section{SUPPLEMENTARY MATERIALS}

Supplementary materials can be found via https://doi.org/ 10.4266/acc.2021.01326.

\section{REFERENCES}

1. Wu Z, McGoogan JM. Characteristics of and important lessons from the coronavirus disease 2019 (COVID-19) outbreak in china: summary of a report of 72314 cases from the Chinese Center for disease control and prevention. JAMA 2020;323:1239-42.

2. Wu C, Chen X, Cai Y, Xia J, Zhou X, Xu S, et al. Risk factors associated with acute respiratory distress syndrome and death in patients with coronavirus disease 2019 pneumonia in Wuhan, China. JAMA Intern Med 2020;180:934-43.

3. Matthay MA, Zemans RL, Zimmerman GA, Arabi YM, Beitler JR, Mercat A, et al. Acute respiratory distress syndrome. Nat Rev Dis Primers 2019;5:18.

4. Slutsky AS, Ranieri VM. Ventilator-induced lung injury. N Engl J Med 2014;370:980.

5. García-de-Acilu M, Patel BK, Roca O. Noninvasive approach for de novo acute hypoxemic respiratory failure: noninvasive ventilation, high-flow nasal cannula, both or none? Curr Opin Crit Care 2019;25:54-62.

6. Crimi C, Noto A, Princi P, Esquinas A, Nava S. A European survey of noninvasive ventilation practices. Eur Respir J 2010;36:362-9.

7. Huang Y, Lei W, Zhang W, Huang JA. High-flow nasal cannula in hypercapnic respiratory failure: a systematic review and meta-analysis. Can Respir J 2020;2020:7406457.

8. Frat JP, Thille AW, Mercat A, Girault C, Ragot S, Perbet S, et al. High-flow oxygen through nasal cannula in acute hypoxemic respiratory failure. N Engl J Med 2015;372:2185-96.

9. Phua J, Weng L, Ling L, Egi M, Lim CM, Divatia JV, et al. Intensive care management of coronavirus disease 2019 (COVID-19): challenges and recommendations. Lancet Respir Med 2020;8:506-17.

10. Alhazzani W, Møller MH, Arabi YM, Loeb M, Gong MN, Fan E, et al. Surviving Sepsis Campaign: guidelines on the management of critically ill adults with Coronavirus Disease 2019 (COVID-19). Intensive Care Med 2020;46:854-87.

11. Duan J, Chen B, Liu X, Shu W, Zhao W, Li J, et al. Use of highflow nasal cannula and noninvasive ventilation in patients with COVID-19: A multicenter observational study. Am J Emerg Med 2021;46:276-81.

12. Franco C, Facciolongo N, Tonelli R, Dongilli R, Vianello A, Pisani L, et al. Feasibility and clinical impact of out-of-ICU noninvasive respiratory support in patients with COVID-19-related pneumonia. Eur Respir J 2020;56:2002130.

13. Wang K, Zhao W, Li J, Shu W, Duan J. The experience of highflow nasal cannula in hospitalized patients with 2019 novel 
coronavirus-infected pneumonia in two hospitals of Chongqing, China. Ann Intensive Care 2020;10:37.

14. Ou X, Hua Y, Liu J, Gong C, Zhao W. Effect of high-flow nasal cannula oxygen therapy in adults with acute hypoxemic respiratory failure: a meta-analysis of randomized controlled trials. CMAJ 2017;189:E260-7.

15. Moher D, Liberati A, Tetzlaff J, Altman DG; PRISMA Group. Preferred reporting items for systematic reviews and meta-analyses: the PRISMA statement. PLoS Med 2009;6:e1000097.

16. Sterne JA, Savović J, Page MJ, Elbers RG, Blencowe NS, Boutron I, et al. RoB 2: a revised tool for assessing risk of bias in randomised trials. BMJ 2019;366:14898.

17. Wells GA, Shea B, O'Connell D, Peterson J, Welch V, Losos M, et al. The Newcastle-Ottawa Scale (NOS) for assessing the quality of nonrandomised studies in meta-analyses [Internet]. Ottawa (ON): Ottawa Hospital Research Institute; 2013 [cited 2021 Dec 10]. Available from: https://www.ohri.ca/programs/clinical_ epidemiology/oxford.asp.

18. Thorlund K, Engstrøm J, Wetterslev J, Brok J, Imberger G, Gluud C. User manual for trial sequential analysis (TSA) [Internet]. Copenhagen: Copenhagen Trial Unit, Centre for Clinical Intervention Research; 2011 [cited 2021 Dec 10]. Available from: https:/ctu.dk/wp-content/uploads/2021/03/2017-10-10-TSAManual-ENG_ER.pdf.

19. Cochrane Collaboration. Review Manager (RevMan) version 5.4. London: Cochrane Collaboration; 2020.

20. Hu HT, Xu S, Wang J, Rao X. Respiratory support in severely or critically ill ICU patients with COVID-19 in Wuhan, China. Curr Med Sci 2020;40:636-41.

21. Wang Z, Ye D, Wang M, Zhao M, Li D, Ye J, et al. Clinical features of COVID-19 patients with different outcomes in wuhan: a retrospective observational study. Biomed Res Int 2020;2020:2138387.

22. Wendel Garcia PD, Fumeaux T, Guerci P, Heuberger DM, Montomoli J, Roche-Campo F, et al. Prognostic factors associated with mortality risk and disease progression in 639 critically ill patients with COVID-19 in Europe: initial report of the international RISC-19-ICU prospective observational cohort. EClinicalMedicine 2020;25:100449.

23. COVID-ICU Group on behalf of the REVA Network and the COVID-ICU Investigators. Clinical characteristics and day-90 outcomes of 4244 critically ill adults with COVID-19: a prospective cohort study. Intensive Care Med 2021;47:60-73.

24. Klein SJ, Bellmann R, Dejaco H, Eschertzhuber S, Fries D, Furtwängler W, et al. Structured ICU resource management in a pandemic is associated with favorable outcome in critically ill
COVID-19 patients. Wien Klin Wochenschr 2020;132:653-63.

25. Grieco DL, Menga LS, Cesarano M, Rosà T, Spadaro S, Bitondo MM, et al. Effect of Helmet noninvasive ventilation vs high-flow nasal oxygen on days free of respiratory support in patients with COVID-19 and moderate to severe hypoxemic respiratory failure: the HENIVOT randomized clinical trial. JAMA 2021;325:1731-43.

26. Routsi C, Magira E, Kokkoris S, Siembos I, Vrettou C, Zervakis D, et al. Hospital resources may be an important aspect of mortality rate among critically ill patients with COVID-19: the paradigm of Greece. J Clin Med 2020;9:3730.

27. ARDS Definition Task Force, Ranieri VM, Rubenfeld GD, Thompson BT, Ferguson ND, Caldwell E, et al. Acute respiratory distress syndrome: the Berlin Definition. JAMA 2012;307:2526-33.

28. Wendel Garcia PD, Aguirre-Bermeo H, Buehler PK, Alfaro-Farias M, Yuen B, David S, et al. Implications of early respiratory support strategies on disease progression in critical COVID-19: a matched subanalysis of the prospective RISC-19ICU cohort. Crit Care 2021;25:175.

29. Koga Y, Kaneda K, Fujii N, Tanaka R, Miyauchi T, Fujita M, et al. Comparison of high-flow nasal cannula oxygen therapy and non-invasive ventilation as first-line therapy in respiratory failure: a multicenter retrospective study. Acute Med Surg 2019;7:e461.

30. Carteaux G, Millán-Guilarte T, De Prost N, Razazi K, Abid S, Thille AW, et al. Failure of noninvasive ventilation for de novo acute hypoxemic respiratory failure: role of tidal volume. Crit Care Med 2016;44:282-90.

31. Grieco DL, Menga LS, Raggi V, Bongiovanni F, Anzellotti GM, Tanzarella ES, et al. Physiological comparison of high-flow nasal cannula and helmet noninvasive ventilation in acute hypoxemic respiratory failure. Am J Respir Crit Care Med 2020;201:303-12.

32. Sztrymf B, Messika J, Bertrand F, Hurel D, Leon R, Dreyfuss D, et al. Beneficial effects of humidified high flow nasal oxygen in critical care patients: a prospective pilot study. Intensive Care Med 2011;37:1780-6.

33. Parke RL, McGuinness SP. Pressures delivered by nasal high flow oxygen during all phases of the respiratory cycle. Respir Care 2013;58:1621-4.

34. Mauri T, Turrini C, Eronia N, Grasselli G, Volta CA, Bellani G, et al. Physiologic effects of high-flow nasal cannula in acute hypoxemic respiratory failure. Am J Respir Crit Care Med 2017;195:1207-15.

35. Esquinas Rodriguez AM, Scala R, Soroksky A, BaHammam A, 
de Klerk A, Valipour A, et al. Clinical review: humidifiers during non-invasive ventilation: key topics and practical implications. Crit Care 2012;16:203.

36. Placidi G, Cornacchia M, Polese G, Zanolla L, Assael BM, Braggion C. Chest physiotherapy with positive airway pressure: a pilot study of short-term effects on sputum clearance in pa- tients with cystic fibrosis and severe airway obstruction. Respir Care 2006;51:1145-53.

37. Lewis SR, Baker PE, Parker R, Smith AF. High-flow nasal cannulae for respiratory support in adult intensive care patients. Cochrane Database Syst Rev 2021;3:CD010172. 